\title{
As produções cinematográficas dos Países Africanos de Língua Oficial Portuguesa
}

Cinematographic productions of Portuguese-Speaking African Countries

https://doi.org/10.34112/2317-0972a2017V35n70p33-49

Marina Oliveira Felix de Mello Chaves ${ }^{1}$

Bruna Suelen Rocha Miranda ${ }^{2}$

Ana Rita de Sá Soveral Padeira ${ }^{3}$

Resumo: O objetivo deste artigo é analisar o Cinema Africano de Língua Portuguesa e sua trajetória como um elemento atuante no cenário político de nações que passaram por profundas transformações desde a segunda metade do século passado até hoje. A partir de um levantamento das produções cinematográficas dos cinco países - Angola, Moçambique, Cabo Verde, Guiné-Bissau e São Tomé e Príncipe -, realizado até agosto de 2011, foram propostas algumas questões e reflexões sobre este assunto ainda pouco estudado.

Palavras-chave: Cinema; África; colonialismo português.

ABSTRACT: This article aims to analyze cinematographic productions of PortugueseSpeaking African Countries and its trajectory as an active element in the political scenario of nations that underwent profound transformations from the second half of the last century until today. Based on a survey of the cinematographic productions of the five countries - Angola, Mozambique, Cape Verde, Guinea Bissau and Sao Tome and Principe - held until August 2011, we have raised a few issues and proposed reflections in order to contribute to the study of this still little studied subject.

Keywords: Cinema; Africa; portuguese colonialism.

1. Universidade de São Paulo, São Paulo, SP, Brasil.

2. Universidade de São Paulo, São Paulo, SP, Brasil.

3. Universidade Aberta, Lisboa, Portugal. 
O cinema africano é uma possibilidade de encontro com culturas que foram silenciadas pelo domínio eurocêntrico colonial durante vários anos e finalmente podem contar suas próprias histórias. Com o controle da língua, de suas imagens e pontos de vista próprios, não somente reescrevem o passado, mas também propõem perspectivas para o presente (SHOHAT; STAM, 2006, p. 358). No entanto, conhecer o cinema africano exige algum esforço. Os filmes são pouco divulgados, muitas exibições ficam restritas a poucos e esporádicos festivais de cinema, de forma que muitos apreciadores e estudiosos restam quase impossibilitados de conhecer essas produções.

Para conhecer as narrativas fílmicas, é imprescindível pesquisar a trajetória dos cineastas e conhecer o contexto histórico e geopolítico de quando esses filmes foram feitos. Mas o esforço para empreender esta busca e ter contato com este cinema é recompensado por obras fílmicas admiráveis, que se revelam muito interessantes, inovadoras e dotadas de altíssima qualidade artística. Conhecer este cinema, além de ser uma oportunidade de ver bons filmes, é uma forma de compreender melhor o universo cultural e intercultural dessas nações, que surpreendem também pelas inúmeras relações com nossa realidade brasileira.

São relevantes e esperadas as correspondências e as semelhanças entre as culturas do Brasil e da África de língua portuguesa. A mesma língua oficial dessas nações representa uma herança do passado colonial em comum, que constituiu motivos e instrumentos de formação - e transformação - social, política e cultural, sobretudo quando se declarou o caráter de resistência ao colonizador português.

No caso dos países africanos, essa resistência se concretizou de forma muito mais violenta e avassaladora em guerras que devastaram povos, espaços e culturas, marcando intensamente qualquer representação posterior. É de se notar também que o processo de independência política no continente africano, em geral, ocorreu em meados das décadas de 1960 e 70 - grosso modo, um século e meio após a culminação da independência do Brasil.

Desse passado histórico bastante recente, restam ainda muitos motivos de indignação e aversão, sobretudo quando se percebem, na constituição social atual, contradições e desacertos que nasceram desse longo período de exploração. Muitos países africanos ainda sofreram veementemente com guerras, guerrilhas e milícias que ocorreram sob influência de partidos políticos, declaradamente moldados de acordo com os interesses norte-americanos e soviéticos, marcados e fortalecidos após a $2^{\mathrm{a}}$ Guerra Mundial. 
Todos esses acontecimentos apontam as fortes marcas do contexto histórico em que as manifestações culturais que atravessaram esse período foram produzidas. De fato, a literatura, o cinema, a música e as artes plásticas acompanharam o fluxo dessas passagens, numa relação conjunta de atuação. A arte e os meios de comunicação ganham, nesse sentido, um caráter de resistência "às pressões estruturais dominantes", conforme Bosi (1996, p. 16, grifo do autor), já que são resultado de "uma consciência grupal operosa e operante que desentranha da vida presente os planos para o futuro" (p. 16). A arte, como depreendemos da fala do escritor angolano Manuel Rui (1987, p. 309), é parte do projeto de transformação social: "interfiro, descrevo para que conquiste a partir do instrumento escrita um texto escrito meu, da minha identidade. [...] Assim reforço a identidade com a literatura. Escrever então é viver. / Escrever assim é lutar".

Os eventos e as narrativas ocorreram juntos no caminho de construção da nação, como instrumentos fundamentais de constituição do imaginário coletivo nacional. Certamente, uma construção - artificial e tensa -, e não um processo natural e pacífico. E diante das transformações políticas ocorridas, se tornou veemente a necessidade de consolidação de uma identidade nacional aos novos países africanos. E, retomando as correlações entre Brasil e África, essa ação aconteceu aos países africanos de língua portuguesa à luz de inspiração brasileira. Os processos históricos que se cruzam em diversos pontos, especialmente com a força da presença do negro escravizado e as heranças portuguesas em comum, refletem dados e fatos que revelam algumas das numerosas coincidências culturais entre tais países.

Todas estas questões nos despertaram o interesse pelo cinema africano. Com este interesse e com a motivação de viabilizar ou facilitar o acesso a esse universo, foi realizado um levantamento das produções cinematográficas dos cinco países: Angola, Moçambique, Cabo Verde, Guiné-Bissau e São Tomé e Príncipe.

O objetivo principal desta atividade foi elaborar um banco de dados que poderia servir de base para a futura organização de um acervo cinematográfico, a fim de ampliar as possibilidades de apreciação e acesso acadêmicos a esse cinema. Muitos estudos se tornam possíveis a partir desta iniciativa, uma vez que cada filme é um objeto de estudo que pode ser aprofundado a partir de diversas abordagens.

A realização deste levantamento fez parte de um projeto de pesquisa liderado pela Profa. Dra. Fabiana Buitor Carelli (Universidade de São Paulo), um trabalho sobre o Cinema Africano de Língua Portuguesa que ela vem conduzindo desde 2009. De sua iniciativa, partiram dois projetos de iniciação científica ("A narração 
cinematográfica como instrumento de construção imagética nacional nas produções cinematográficas dos países de língua portuguesa. Uma análise do filme O testamento do sr. Napumoceno, de Francisco Manso", desenvolvido por Bruna Suelen Rocha Miranda, e "As produções cinematográficas dos Países Africanos de Língua Portuguesa”, desenvolvido por Marina Oliveira Felix de Mello Chaves) e uma dissertação de mestrado ("O cinema e os Países Africanos de Língua Oficial Portuguesa”, desenvolvido por Marina Oliveira Felix de Mello Chaves).

O levantamento consistiu em três etapas principais: buscar os títulos e as fichas técnicas, organizar os dados encontrados e, por fim, adquirir os filmes. Dos acervos físicos visitados nessas buscas, destacam-se: a Casa das Áfricas e a Cinemateca Brasileira, onde foram encontradas informações importantes para o trabalho. A internet foi o principal veículo para realizar as pesquisas; inúmeros sites foram visitados e consultados para coletar os dados mapeados neste levantamento. Dessas buscas virtuais, destacam-se: os jornais de notícias locais, os blogs e os centros de estudos - sobretudo portugueses, franceses, ingleses e norte-americanos - interessados nas culturas africanas, e as divulgações dos festivais de cinema.

Dessa forma, coletando informações dispersas, os filmes foram encontrados e catalogados. Cada filme possui uma ficha técnica, preenchida com os seguintes campos: título do filme, nome do diretor, país(es) de (co)produção, ano, metragem, classificação (ficção / documentário) e sinopse. Para a organização e classificação dos dados encontrados, foi privilegiado o país de produção do filme, em primeiro lugar. Em seguida, a nacionalidade do cineasta. E, por último, a temática do filme.

Portanto, quais são estes filmes, o que retratam e quem são seus realizadores foram as principais perguntas que acompanharam o trabalho. Porém, conforme a pesquisa foi se desenvolvendo, foi interessante perceber que, a cada nova informação encontrada, novos estímulos eram despertados, pois os caminhos percorridos para encontrar algumas respostas acabavam gerando outras dúvidas.

Por que estes filmes são tão pouco divulgados, qual é o público que assiste a eles, qual é o interesse das instituições estrangeiras que os financiam, qual é o papel dos festivais na divulgação dos filmes? Assim, procurando entender essas questões, a pesquisa adquiriu novos contornos, que ampliaram e enriqueceram o trabalho. E então, foi preciso recorrer a uma descrição histórica da cinematografia em questão.

Quase todas as obras pesquisadas são comprometidas com questões sociais, históricas e políticas. Mas aqueles anteriores à década de 1960 foram produzidos pelas autoridades europeias, que estavam engajadas em produzir filmes publicitários, 
missionários e pedagógicos, mais preocupados em reafirmar a hierarquia cultural eurocêntrica em relação à África, a favor do sistema colonial.

De fato, os filmes proximamente posteriores a esse período são aqueles que tratam de uma ideologia política revolucionária, que fazia parte do momento de independência. Nesse período, os realizadores dos filmes procuravam se comunicar tanto com o público local que assistia a eles e era convidado a se mover a favor da causa proposta, quanto com o público exterior, que deveria tomar conhecimento da vigência da reação ao colonialismo.

O ideal da negritude se encontra no centro das primeiras experiências cinematográficas africanas e faz parte de um sonho de convivência e compreensão inter-racial no mundo. O momento concentrava também uma tentativa de superar o sentimento interno de inferioridade, nutrido por séculos de escravidão e de colonialismo. Assim, o cineasta africano, como também os demais artistas, foi convocado a ter um compromisso com a cultura local, inserindo sua obra num diálogo entre as diferentes culturas e, desse modo, participando de um universalismo das civilizações.

$\mathrm{O}$ "cinema nacional" nos países africanos de língua portuguesa foi construído como parte do plano da luta pela independência e a partir de iniciativas e esforços de diretores e produtores estrangeiros. Conforme Fernando Arenas (2011) descreve, diferente de outros países africanos, como Gana, Nigéria e Congo, em que os ingleses e os belgas facilitaram a produção para o desenvolvimento do cinema após a independência, os portugueses não deixaram nenhuma infraestrutura ou qualquer treinamento técnico nos territórios africanos. De fato, a produção cinematográfica dos países lusófonos é muito menor que a dos países francófonos e anglófonos (ARENAS, 2011).

As condições econômicas, materiais e geopolíticas para o nascimento e o subsequente desenvolvimento do cinema nas colônias portuguesas foram muito mais precárias que em outros países africanos. De um lado, havia a falta de treinamento em filmagens e de infraestrutura; do outro, os propósitos da MPLA em Angola e da FRELIMO em Moçambique inspiraram uma onda de solidariedade internacional. Realizadores e ativistas da França, da Iugoslávia, de Cuba e da União Soviética aderiram à produção do cinema nesses países, concentrando seus esforços e talentos em visões emancipatórias, a favor dos movimentos de libertação. Logo, o filme foi desenvolvido como uma ferramenta ideológica estratégica para documentar, educar e disseminar, tanto para o povo africano quanto para a comunidade internacional, informações sobre as guerras anticoloniais e sobre a condição histórica do povo africano (ARENAS, 2011). 
Em Angola, quando o MPLA chegou ao poder, direcionou recursos para a produção de filmes a serviço de uma causa nacional orientada pelo marxismo-leninismo. Assim, vários documentários foram feitos nessa ordem. No entanto, com a guerra civil que devastou o país, a produção de filmes em Angola ficou estagnada por cerca de 20 anos. Moçambique, por outro lado, exerceu um papel pioneiro na história do cinema africano pós-colonial. Segundo Leonor Areal e Sérgio Tréfaut (2008, p. 66),

[...] a Frelimo, que soubera utilizar o cinema como meio de afirmação e de pressão diplomática durante a luta contra o poder colonial português, entende que após a independência esta função quase "propagandística" deve ser redireccionada para o próprio país. Na ausência de televisão, só o cinema poderia ter essa função de construir a auto-imagem de um país. Era necessário criar um sentimento de unidade nacional que fizesse abandonar as rivalidades tribais.

Quando o partido FRELIMO iniciou seu governo no país, providenciou a criação do Instituto de Cinema de Moçambique, em 1975. O governo convidou Rui Guerra - um dos realizadores do Cinema Novo brasileiro, nascido em Moçambique - para ser diretor desse instituto. $O$ cinema foi usado como instrumento vital para o propósito da propaganda educativa e ideológica no processo de construção simbólica da nova nação-estado independente, como mostra o filme Kuxa Kanema: $o$ nascimento do cinema (2003), da cineasta portuguesa Margarida Cardoso.

$\mathrm{O}$ instituto se tornou um laboratório que reuniu talentos e visões de inúmeros cineastas moçambicanos e estrangeiros, roteiristas, produtores, editores e técnicos. Além disso, os diretores franceses vanguardistas Jean Rouch e Jean Luc Godard se envolveram em projetos, junto com o Instituto, a favor do desenvolvimento da produção cinematográfica naquele contexto de limitações tecnológicas e financeiras. Rouch desenvolveu o projeto Super 8 e Godard levou ao país a produtora Sonimages. No entanto, esses projetos não foram adiante, por desentendimentos ideológicos ou relacionados aos seus custos (ARENAS, 2011).

Em entrevista apresentada no filme Kuxa Kanema, o cineasta Licínio Azevedo conta que a chegada de Godard provocara forte impacto no ambiente cinematográfico: "[d]izia que o cinema é contabilidade, tem que se gastar o mínimo de película e obter o máximo na montagem. Nós até dizíamos, a brincar: filmar um minuto e montar dois. Godard serviu para ensinar: 'Utiliza o máximo do que está à tua frente”. 
O instituto se tornou um centro de produção de jornais, documentários e filmes. O Kuxa Kanema foi um dos seus projetos mais conhecidos, criado como uma iniciativa de cinema a serviço dos interesses do povo africano, neste caso, a construção de nação sob as regras da FRELIMO e sua visão de uma república socialista. $O$ projeto organizou, durante toda a década de 1980 , jornais semanais de 10 minutos que foram mostrados ao redor do país em salas de cinema ou em vans organizadas pela União Soviética em áreas rurais remotas.

Segundo Leonor Areal e Sérgio Tréfaut (2008, p. 67):

Naquele tempo havia a consciência aguda de que a informação e os filmes produzidos actuavam diretamente sobre o público. E havia o desejo de acabar com a dominante ideológica que o cinema comercial transportava. "Todos fomos educados pela imagem imperialista", declarou alguns anos mais tarde Pedro Pimenta. "Existe uma tendência para imitar a imagem dominante. Mas não se pode usar a mesma imagem e meramente mudar a ideologia. É necessário mudar a imagem para realmente produzir uma nova ideologia.”

O Instituto de Cinema de Moçambique decaiu em 1991, após um incêndio que destruiu equipamentos de filmagem, salas e laboratórios de edição e processamento. Esse acontecimento, aliado à morte do líder carismático fundador Samora Machel, acabou apagando e enfraquecendo a utopia de uma sociedade livre e igualitária em que o cinema exerceria um papel de destaque.

Segundo Margarida Cardoso (2008, p. 34),

aquele local destruído e paralisado no tempo, a estranha inutilidade daqueles registros do passado praticamente esquecidos, tudo me pareceu representar na perfeição uma idéia mais global daquilo em que se tinha transformado o país. "Tudo o que fizemos está ali guardado, naquelas mesmas latas de filme, com as mesmas fitas à volta... É como se fosse uma coisa que existe, mas que no fundo não existe. Essa é a imagem do país" - disse-me uma cineasta do INC, quando a entrevistei.

Assim aconteceu o nascimento do cinema em Moçambique. O cinema é uma linguagem universal, aproveitada de formas infinitas. A esse respeito, Jean-Luc Godard comenta: "Em Moçambique existem também coisas únicas. Nesse sentido, se formos capazes de as filmar, todo o mundo as vai entender. Não acredito que 
exista uma linguagem russa ou moçambicana. Os homens, a mão e o olho é que são moçambicanos" (GODARD, 2008, p. 73).

Durante o período de guerras civis, que aconteceram entre conflitos internos e regionais e influenciadas por fatores globais geopolíticos, relacionados em parte com a Guerra Fria e com o Apartheid, houve uma interrupção nas produções cinematográficas.

Em seguida, são aqui apresentadas breves descrições dos resultados do levantamento realizado:

\section{Moçambique}

O Instituto Nacional de Cinema criado no período pós-independência se tornou campo de treinamento para cineastas que emergiram ali e continuaram a construir o legado de comprometimento social que sempre permeou o cinema moçambicano, mesmo após as mudanças ideológicas e políticas por que passou o país desde os anos 1980. Desta fase, destacam-se os filmes Mueda, memória e massacre (1979), de Ruy Guerra, O tempo dos leopardos (1985), de Zdravko Velimorovic e Camilo de Sousa e $O$ vento sopra do norte (1987), de José Cardoso.

Depois que o INC reduziu suas atividades, iniciou-se uma nova fase no cine$\mathrm{ma}$, em que os cineastas passaram a buscar apoio e patrocínio, recorrendo, quase sempre, a instâncias externas.

O mais produtivo cineasta desde o início dos anos 1990 foi o brasileiro Licínio Azevedo, que vive em Moçambique há mais de 30 anos e realizou um grande número de filmes. Destacam-se seus longas-metragens de ficção O grande bazar (2005) e Virgem Margarida (2012). Orlando Mesquita trabalha com Licínio Azevedo na produtora Ebano Multimedia e realizou mais de 30 filmes como editor, produtor e diretor. João Ribeiro desenvolveu vários projetos de adaptação das obras literárias de Mia Couto para o cinema, com destaque para o longa-metragem $O$ último voo dosflamingos (2009). Sol de Carvalho se destaca por ter dirigido $O$ jardim do outro homem (2006), o longa-metragem de ficção de maior orçamento já produzido no país (cerca de 1 milhão de dólares).

Merecem destaque os filmes produzidos por cineastas portugueses, que se relacionam com Moçambique: O gotejar da luz (2002), de Fernando Vendrell, Kuxa Kanema (2003), de Margarida Cardoso, A costa dos murmúrios (2004), de Margarida Cardoso, Terra sonâmbula (2007), de Teresa Prata, e Tabu (2012), de Miguel Gomes. 
ANGOLA

De forma semelhante aos moçambicanos, os cineastas angolanos também se aliaram ao comprometimento social em suas artes. No entanto, a produção angolana sofreu consequências muito piores, devido à guerra civil que durou muitos anos em Angola. Assim, nos anos 90, o cinema praticamente desapareceu e foi retomado após os anos 2000, com o desenvolvimento da Televisão Pública de Angola e com a reativação do Ministério Angolano de Cultura e do Instituto de Multimídia e Filme Angolano.

Dos filmes que emergiram das influências internacionais a favor dos movimentos nacionais de libertação nas colônias africanas portuguesas, o filme de ficção mais importante foi Sambizanga (1972), de Sarah Maldoror, de Guadalupe, baseado no romance do escritor angolano José Luandino Vieira, A vida verdadeira de Domingos Xavier.

Rui Duarte de Carvalho foi um escritor e antropólogo que realizou filmes marcantes nas décadas de 1970 e 1980, com destaque para o longa-metragem de ficção Nelisita (1983). Após o fim da guerra em 2002, destacam-se três filmes, que obtiveram repercussão internacional: O herói (2004), de Zezé Gamboa; Na cidade vazia (2004), de Maria João Ganga; e O comboio da Canhoca (2004), de Orlando Fortunato. Recentemente, houve lançamentos grandes no cinema de Angola, com destaque para O grande Kilapy (2012), de Zezé Gamboa, e Njinga, a rainha de Angola (2013), de Sergio Graciano.

\section{GUINÉ-BISSAU}

Deste país, o maior destaque no cinema deve se dirigir ao cineasta Flora Gomes, que conquistou reconhecimento internacional com obras de altíssima qualidade. Destacam-se seus cinco longas-metragens de ficção: Mortu Nega (1988); Udju azul di Yonta (1991); Po di Sangui (1996); Nha Fala (2002) e República dimininus (2012).

Destaca-se também o documentário As duas faces da guerra (2007), de Diana Andringa e Flora Gomes.

\section{Cabo Verde}

Nos anos 1990 houve muitas coproduções envolvendo Cabo Verde, Portugal e Brasil. Destacam-se: Casa de lava (Pedro Costa, 1994); Ilhéu de contenda (Leão 
Lopes, 1995); O testamento do sr. Napumoceno (Francisco Manso, 1997); e Fintar o Destino (Fernando Vendrell, 1998).

\section{São Tomé e Príncipe}

A produção em São Tomé e Príncipe é quase inexistente. Há o realizador Ângelo Torres, que atuou no filme Nha Fala (2002), de Flora Gomes, e vem desenvolvendo sua carreira no cinema. Há também filmes que relatam alguns episódios ocorridos no país, mas não foi encontrada nenhuma produção de destaque que pudesse ser classificada nesse país.

\section{Filmes AFRicanos}

Muitos críticos situam o nascimento do cinema africano negro nos anos 1950 e 1960, quando a maioria das colônias europeias se tornou independente. Os filmes Afrique sur Seine (1957), dos diretores senegaleses Paulin Soumanou Vieyra e Mamadou Sarr, em conjunto com Borom Sarret (1962), de Ousmane Sembene, foram considerados filmes de fundação, já que foram os primeiros dirigidos por diretores negros.

Dentre os principais diretores africanos, destacam-se: Ousmane Sembene (Senegal), Idrissa Ouedroago (Burkina Faso), Abderrahmane Sissako (Mauritania/ Mali), Flora Gomes (Guiné-Bissau) e Jean-Pierre Bekolo (Camarões).

Dos filmes africanos que atingiram reconhecimento no circuito internacional, destacam-se: Yaaba (1989) e Tilai (1990), de Idrissa Ouedraogo; Yeelen (1987), de Souleymane Cissé (Mali); e The gods must be crazy (1980), de Jamie Uys.

A Nigéria se destaca também por apresentar um volume grande de produção no cinema, sendo conhecida como Nollywood.

O cinema é, assim, uma plataforma de análise dos acontecimentos políticos que ocorreram nesses países. Atualmente, o cinema dos países africanos de língua portuguesa tende a não se confinar numa dimensão estética e formal de entretenimento. As produções apresentam um fundo reflexivo, impulsionado por um comprometimento ético, por questões sociais, processos históricos e desenvolvimentos culturais em níveis do indivíduo, coletivo, nacional e continental, propondo discussões sobre como a cultura tradicional pode conviver com a sociedade moderna e globalizada e problematizando as dificuldades que o capitalismo trouxe a esses países. 
As guerras e suas consequências, as atrocidades do sistema colonial e as turbulentas situações sociais e políticas por que esses países passam até hoje estão sempre presentes de alguma forma nas representações culturais e, assim também, nos filmes.

Além disso, é recorrente nesse cinema a questão religiosa. A relação com os espíritos faz parte dessas culturas, conferindo a suas expressões artísticas um lado fantástico e onírico, que, na maioria das vezes, é exótico para os ocidentais. A relação com os antepassados é um tema central na construção da identidade cultural dessas sociedades, mesmo aquelas já urbanizadas.

Outra questão que chama a atenção neste cinema é relacionada à língua. Apesar de este levantamento se referir aos países africanos de língua portuguesa, muitas vezes a língua nativa é a que predomina nos filmes e nas sociedades. O português é a língua oficial e representa a unidade entre as inúmeras línguas faladas ali. No entanto, quando as filmagens se direcionam, principalmente, às zonas rurais, suburbanas ou marginais, o trabalho de tradução se torna necessário.

Mas este cinema continua a sobreviver, confrontando os desafios financeiros e de infraestrutura que são comuns aos demais países africanos. É interessante refletir que, mesmo num período bem posterior às independências, o Cinema Africano de Língua Portuguesa continua fortemente dependente do apoio e da realização estrangeiros.

O destino das nações africanas é, de fato, irreversivelmente ligado às heranças do colonialismo, aos paradoxos do pós-colonialismo e às pressões e às promessas, trazidos à força pela globalização. E esse destino influencia não somente as temáticas dos filmes, mas também a produção, a distribuição e o consumo do cinema na África.

Apesar de haver uma abundância de histórias para contar e um vasto talento a ser aproveitado, o cinema continua a ser muito dependente de auxílios que emanam principalmente da Europa. Essa dependência também é indicada pelos títulos, que muitas vezes aparecem traduzidos para outras línguas (francês e inglês, principalmente), o que demonstra que o público desses filmes dificilmente é o público local. Os subsídios estrangeiros são essenciais não somente às filmagens e às produções, mas também à disseminação desses filmes no circuito internacional, o que está praticamente restrito aos festivais internacionais de cinema.

Assim, se o cinema africano nasceu como um cinema engajado, comprometido com as políticas de descolonização e aliado aos novos governos africanos em desenvolvimento, atualmente esse cinema sobrevive numa relação de dependência e cooperação cultural que os países europeus mantêm com suas ex-colônias. 
Se, por um lado, essa política de ajuda internacional fornece os recursos para a sustentação do cinema africano, por outro lado, acaba por dificultar a emergência de uma indústria cinematográfica própria. Os governos africanos limitam seus recursos, o setor privado local também não se envolve com a produção cultural, e, assim, retarda-se a consolidação do cinema próprio, que poderia operar como alternativa ao desenvolvimento econômico e cultural das nações africanas. Dessa forma, o apoio ocidental é ambíguo, carregado de contradições e pode ser questionado.

A questão problemática não reside somente no fato de ser um cinema assistido por ajudas externas - o que não é, de forma alguma, característica exclusiva dos cinemas africanos. $\mathrm{O}$ ponto a ser discutido é em que medida os planos temático e ideológico são afetados por uma pressão de adaptação do conteúdo aos interesses daqueles que ajudam.

Mesmo que essa cooperação estrangeira atue ora como bondoso incentivo à produção cultural, ora como uma forma de compensar o indigno passado colonial, o princípio dessa ajuda não deixa de partir de uma relação de centro em relação ao outro. A cultura e o cinema feitos pelos africanos são diferentes, exóticos e interessantes aos olhos da crítica ocidental, que espera por novidades artísticas que ainda correspondam às normas de qualidade internacional.

Assim, a atividade cinematográfica africana é produzida com vínculo internacional, e da mesma forma é consumida. Com possibilidades restritas, os filmes africanos dependem também dos festivais internacionais. Muitas vezes, o lançamento comercial dos filmes é quase inexistente, e os festivais acabam atuando como uma alternativa para distribuir e promover os filmes africanos; às vezes são seus únicos veículos de exibição. Os festivais, portanto, exercem um papel fundamental - e inseparável - à existência e à vitalidade do cinema africano. Além de possibilitar o encontro dos filmes, gerar debates e discussões e montar o espaço para que os cineastas promovam o contato com produtores, os filmes africanos também alimentam e garantem a conservação, a continuidade e o crescimento desses festivais.

No entanto, os festivais também exercem um papel decisivo à compreensão e à aceitação das imagens africanas. Ao avaliar os filmes, é preciso atentar à excessiva importância dos festivais, associada ao trabalho dos cineastas africanos. Se, por um lado, favorecem o diálogo e a compreensão, na medida em que representam uma possibilidade de mostrar ao público ocidental uma forma como os próprios africanos se veem e julgam sua situação e sua história, por outro lado, o sentimento de curiosidade, de afeição e de exotismo em relação aos filmes africanos continua 
envolvendo essa relação. Esse sentimento, muitas vezes, é nutrido pela atitude de cineastas que buscam satisfazer às expectativas do público dos festivais e acabam submetendo o cinema africano a uma condição de refém da crítica ocidental, evidenciando valores artificiais e estereotipados sobre os países africanos. O cinema se desvirtua, quando um filme é arquitetado em função de oferecer aquilo que o público gostaria de ver, e não de atender à intenção expressiva original de seu realizador.

São também ambíguas as relações entre a crítica ocidental eurocêntrica e os filmes africanos. $\mathrm{O}$ valor e a estética do cinema africano são reconhecidos em uma leitura ocidental portadora de ideologia e expectativas próprias, que projeta representações imaginárias próprias sobre as produções fílmicas africanas, sempre esperadas como "autênticas”. Muitas vezes, esses olhares apenas reforçam a diferença e a incapacidade de apreciação e compreensão das expressões autônomas do outro.

A avaliação crítica eurocêntrica, que exalta o exotismo da cinematografia africana, é indesejada, na medida em que reforça clichês que impedem um exercício reflexivo mais profundo quanto ao que essas culturas podem acrescentar sobre a singularidade ou universalidade da arte. Essa crítica que decorre de uma apreciação simplista, que espera uma cultura imaginada pré-moldada, também reduz e classifica o cinema africano como um todo unificado. As propostas, as temáticas e os estilos seriam, assim, todos iguais, e não faria diferença assistir a um ou a outro filme.

É interessante observar que os festivais referidos costumam se apresentar sob o termo genérico "festival de cinema africano". É verdade que muitas produções compartilham das mesmas características formais e temáticas. Além disso, ainda é tão incipiente a produção de alguns países, que não seria possível organizar festivais exclusivos para eles. Mas nem por isso se pode inferir que não haja variedade e diversidade entre as propostas fílmicas e que as preocupações político-sociais sejam as mesmas em todo o continente. O que há são diferentes cinemas africanos, buscando encontrar espaço e soluções para se consolidar.

Apesar de tudo isso, quando se assiste aos filmes, percebe-se com clareza que são importantes para a rica vida cultural desses países. As narrativas são cuidadosamente desenvolvidas, de forma a acender discussões e reflexões, provocar mudanças de comportamentos e, por fim, construir um imaginário coletivo acerca dessas nações.

O campo cultural do cinema africano em todos os níveis - produção, distribuição, consumo e crítica - se desenvolve, portanto, entre uma multiplicidade de forças: a complexa relação entre os governos europeus, as instituições culturais 
fílmicas e as audiências e críticas estrangeiras. Entre todas essas forças, os realizadores africanos contam histórias que impressionam, comovem e evidenciam as pressões existentes entre os filmes, a história, a cultura e as políticas das nações africanas.

\section{REFERÊNCIAS}

AREAL, L.; TRÉFAUT, S. Laboratório Moçambique - Cinema em revolução. Docs.pt, n. 7, p. 6669, out, 2008.

BOSI, A. Dialética da colonização. São Paulo: Companhia das Letras, 1996.

CARDOSO, M. Kuxa Kanema o nascimento do cinema - 5 perguntas a Margarida Cardoso. Docs. pt, n. 7, p. 34-35, out. 2008.

CHAVES, M. O. F. M. O cinema e os Países Africanos de Língua Oficial Portuguesa. 2017. 160 f. Dissertação (Mestrado em Letras) - Faculdade de Filosofia, Letras e Ciências Humanas, Universidade de São Paulo, São Paulo, 2017.

DIAWARA, M. African cinema: politics and culture. Bloomington: Indiana University Press, 1992.

GODARD, J.-L. Entrevista a Jean-Luc Godard. Docs.pt, n. 7, p. 72-75, out. 2008. Entrevista concedida a Luís Carlos Patraquim e Licínio Azevedo em Maputo, 1978.

SHOHAT, E.; STAM, R. Crítica da imagem eurocêntrica. Multiculturalismo e Representação. São Paulo: Cosac Naify, 2006.

\section{Filmografia}

A COSTA dos murmúrios. Direção: Margarida Cardoso. Portugal, 2004, 115 min., drama, color.

AS DUAS faces da guerra. Direção: Diana Andringa e Flora Gomes. Produção: LX Filmes. Roteiro: Diana Andringa. Portugal, 2007, 100 min., doc., color.

BOROM Sarret. Direção: Ousmane Sembène. Intérpretes: Ly Abdoulay e Albourah. Roteiro: Ousmane Sembène. Senegal, 1963, 2omin., drama, p\&b.

FINTAR o destino. Direção: Fernando Vendrell. Portugal/Cabo Verde, 1998, 77 min., drama, color. ILHÉU de Contenda. Direção: Leão Lopes. Cabo Verde, 1995, 110 min., drama, color.

KUXA Kanema. Direção: Margarida Cardoso. Produção: Arte France Cinéma, Filmes do Tejo, Radio Télévision Belge Francophone (RTBF). Portugal, 2003, 52 min., doc., color.

LA NOIRE de.... Direção: Ousmane Sembène. Produção: Filmi Domirev e Les Actualités Françaises. Intérpretes: Mbissine Thérèse Diop, Anne-Marie Jelinek, Robert Fontaine e outros. Roteiro: Ousmane Sembène. Senegal, 1966, 65 min., drama, p\&b.

MORTU nega. Direção: Flora Gomes. Guiné-Bissau, 1988, 92 min., drama.

MUEDA, memória e massacre. Direção: Ruy Guerra. Produção: INC. Intérpretes: Romao Canapoquele, Filipe Gunoguacala, Mauricio Machimbuco. Roteiro: Calisto Dos Lagos. Moçambique, 1981, 80 min., drama, p\&b.

NA CIDADE Vazia. Direção: Maria João Ganga. Angola, 2004, 78 min., drama, color. NELISITA. Direção: Ruy Duarte de Carvalho. Angola, 1982, 90 min., drama, p\&b. 
NHA Fala. Direção: Flora Gomes. Guiné-Bissau, 2004, 110 min., drama, color NJINGA, Rainha de Angola. Direção: Sergio Graciano. Angola, 2013, 109 min., drama, color.

O GOTEJAR da Luz. Direção: Fernando Vendrell. Portugal/Moçambique, 2002, 99 min., drama, color.

O GRANDE Bazar. Direção: Licínio Azevedo. Moçambique, 2005, 58 min., drama, color.

O GRANDE Kilapy. Direção: Zezé Gamboa. Angola/Brasil/Portugal, 2012, 100 min., drama, color.

O HERÓI. Direção: Zezé Gamboa. Angola/Portugal/France, 2005, 97 min., drama, color.

OJARDIM do Outro Homem. Direção: Sol de Carvalho. Moçambique, 2006, 80 min., drama, color.

O TEMPO dos leopardos. Direção: Zdravko Velimorovic. Produção: Avala Film. Intérpretes: Armando Loya, Ana Mazue, Santos Mulungo. Roteiro: Licinio Azevedo, Luis Patraquim, Branimir Scepanovic, Zdravko Velimirovic. Moçambique/Iugoslávia, 1985, 95 min., drama, color.

O TESTAMENTO do Senhor Napomuceno. Direção: Francisco Manso. Portugal/Cabo Verde, 1999, 110 min., drama, color.

O VENTO sopra do norte. Direção: José Cardoso. Produção: INC. Moçambique, 1987, 90 min., drama, p\&b.

PO di Sangui. Direção: Flora Gomes. Guiné-Bissau, 1996, 90 min, drama, color.

REPÚBLICA di mininus. Direção: Flora Gomes. Portugal/França, 2012, 78 min., drama, color.

SAMBIZANGA. Direção: Sarah Maldoror. Produção: Isabelle Films. Intérpretes: Domingos de Oliveira, Elisa Andrade, Jean M’Vondo. Roteiro: Claude Agostini. Angola/França, 1972, 102 min., drama, color.

TABU. Direção: Miguel Gomes. Portugal, 2012, 118 min., drama, color.

TERRA Sonâmbula. Direção: Teresa Prata. Moçambique, 2007, 97 min., drama, color.

THE gods must be crazy. Direção: Jamie Uys. África do Sul, 1980, 109 min., ação, color.

TILAI. Direção: Idrissa Quedraogo. Burkina Faso, 81min, 1990, drama, color.

UDJU azul di Yonta. Direção: Flora Gomes. Guiné-Bissau/França/Portugal, 1992, 90 min., drama, color.

ÚLTIMO vôo do flamingo. Direção: João Ribeiro. Moçambique, 2009, 90 min., drama, color.

VIRGEM Margarida. Direção: Licínio Azevedo. Moçambique, 2012, 87 min., drama, color.

YAABA. Direção: Idrissa Quedraogo. Burkina Faso, 1989, 90 min., drama, color.

YEELEN. Direção: Souleymane Cissé. Mali, 1987, 105 min., drama/fantasia, color.

\section{LEITURAS COMPLEMENTARES}

ANDERSON, B. Comunidades imaginadas. São Paulo: Companhia das Letras, 2008.

APPIAH, K. A. The invention of Africa. In: . In my father's house: Africa in the philosophy of culture. London: Methuen, 1992; New York: Oxford University Press, 1992.

ARENAS, F. Lusophone Africa: beyond independence. Minneapolis: University of Minnesota Press, 2010.

BELLO, M. do R. L. Narrativa literária e narrativa fílmica. O caso de Amor de Perdição. Lisboa: Fundação Calouste Gulbenkian; FCT, 2008.

BENJAMIN, W. Magia e técnica, arte e política. 3. ed. São Paulo: Brasiliense, 1987.

CABAÇO, J. L. Moçambique: identidade, colonialismo e libertação. São Paulo: UNESP, 2009. 
CANDIDO, A. Formação da literatura brasileira. Rio de Janeiro: Ouro sobre Azul, 2007.

CANDIDO, A. et al. A personagem de ficção. 5. ed. São Paulo: Perspectiva, 1976.

FERRO, M. Cinema e história. São Paulo: Paz e Terra, 1992.

GRILO, J. M. O homem imaginado. Cinema, acção, pensamento. Lisboa: Livros Horizonte, 2006.

GRUZINSKI, S. O pensamento mestiço. São Paulo: Companhia das Letras, 2001.

LEITE, A. M. Literaturas africanas e formulações pós-coloniais. São Paulo: Colibri, 2003.

MARTIN, M. A linguagem cinematográfica. São Paulo: Brasiliense, 1990.

MBEMBE, A. Introduction: time on the move. In: MBEMBE, A. On the postcolony. Berkeley:

University of California Press, 2001.

MILLER, C. Introduction: Reading through western eyes. In: MILLER, C. Theories of Africans. Chicago: University of Chicago Press, 1990.

MUDIMBE, V. Y. Which idea of Africa?. In: MUDIMBE, V. Y. The idea of Africa. Bloomington: Indiana University Press, 1994.

NAVARRO, A. R. P. Da ficção literária à representação cinematográfica: imagens e estereótipos de uma realidade. In: COLÓQUIO NACIONAL LITERATURA E HISTÓRIA: PARA UMA PRÁTICA INTERDISCIPLINAR, 1., Lisboa, 2002. Actas ... Lisboa: Universidade Aberta, 2005. p. 107-114.

PERES, P. Introduction. In: PERES, P. Transculturation and resistance in lusophone African literature.

Gaineesville: Florida University Press, 1997.

REIS, C.; LOPES, A. C. Dicionário de narratologia. Coimbra, Almedina: 1991.

STAM, R. A literatura através do cinema. Belo Horizonte: UFMG, 2008.

TARKOVSKY, A. Esculpir o tempo. São Paulo: Martins Fontes, 1998.

THACKWAY, M. Africa shoots back: alternative perspectives in Sub-Saharan African film. Bloomington: Indiana University Press, 2003.

XAVIER, I. Alegorias do subdesenvolvimento. São Paulo: Brasiliense, 1993. . A experiência do cinema. São Paulo: Graal, 2003.

\section{Sobre as aUtoras}

Marina Oliveira Felix de Mello Chaves é graduada em Letras, com habilitação em Português e Linguística (Universidade de São Paulo) e tem mestrado em Estudos Comparados de Literaturas de Língua Portuguesa (Universidade de São Paulo). E-mail:marinafelix84@msn.com.

Bruna Suelen Rocha Miranda é graduada em Letras (Universidade de São Paulo), tem pós-graduação em Literatura e Língua Portuguesa (Universidade Presbiteriana Mackenzie).

E-mail: bruna.rocha.miranda@gmail.com. 
Ana Rita de Sá Soveral Padeira é graduada em Letras (Universidade Nova de Lisboa), tem Mestrado em Estudos Anglo-Portugueses (Universidade Nova de Lisboa) e Doutorado em Literatura Portuguesa (Universidade Aberta). É professora da Universidade Aberta na área de literatura portuguesa e literaturas de expressão portuguesa, bem como de cinema e teatro portugueses. Tem experiência nas áreas literatura e cultura portuguesas, história do cinema português e teatro português até o século XVIII.

E-mail: ana.padeira@uab.pt.

Recebido em 12 de janeiro de 2017 e aprovado em 02 de março de 2017. 